\title{
Multi-Segment Foam Flow Field in Ambient Pressure Polymer Exchange Membrane Fuel Cell
}

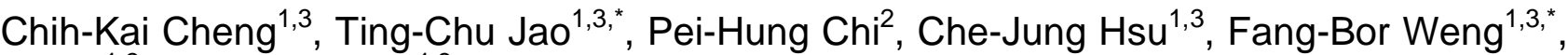 \\ Ay $\mathrm{Su}^{1,3}$ and Tsao Heng ${ }^{1,3}$
}

${ }^{1}$ Department of Mechanical Engineering, Yuan Ze University, Taoyuan 320, Taiwan

${ }^{2}$ Department of Mechanical Engineering, Lee-Ming Institute of Technology, Taipei 243, Taiwan

${ }^{3}$ Fuel Cell Center, Yuan Ze University, Taoyuan 320, Taiwan

\begin{abstract}
In order to produce low-cost flow field plates for polymer electrolyte membrane fuel cells, we used nickel foam in this study rather than conventional flow field. Nickel foam has high electron conductivity, thermal conductivity, and mechanical strength. Electrochemical impedance spectrum analysis is carried out to evidence the use on flow field plates of nickel foam. From the impedance fitting results, the nickel foam cases showed the lower contact resistance than the serpentine. However, such plates have poor performance at low temperatures and ambient pressure. In order to overcome this, a multi-segment foam flow field is designed in this study. This increased the performance of the polarization curve by $70 \%$ from 162 to $275.5 \mathrm{mw} \mathrm{cm}^{-2}$ than the original nickel foam design. Also, the mass transfer resistance was reduced, and the Warburg impedance value of the operation voltage decreased by $0.4 \mathrm{~V}$. The numerical analysis results demonstrate that increased segment numbers can increase the performance of the multi-segment foam flow field.
\end{abstract}

Keyword: Metal foam, fuel cell, flow field, low temperatures.

\section{INTRODUCTION}

Because global warming continues to be a serious problem, new clean power sources, such as polymer electrolyte membrane fuel cells (PEMFCs), has become a major subject of study. Flow field plates are one of the most important components of the PEMFC stack, and they account for over $80 \%$ of the total weight and volume of the stack. The function of flow field plates is to provide flow channels that distribute fuel to the gas diffusion layer (GDL). The geometrical arrangement plays an important role in performance and water flooding. The ratio of the channel area to the rib area is an important parameter correlating to the flow field layout. Generally, a greater rib area decreases the contact resistance but sacrifices fuel transportability. Conversely, a greater channel area has better fuel transport but higher contact resistance. Therefore it is difficult to design a perfect flow field with both a high contact area and high fuel transportability.

Metal foam, which has a random mesh structure, is an extremely light and porous material. Its unique characteristics, such as high tensile strength, high porosity, and a high surface area to volume ratio, enable it to serve a variety of engineering applications [1]. For example, metal foam has been applied in

\footnotetext{
*Address correspondence to this author at the Department of Mechanical Engineering, Yuan Ze University, Taoyuan 320, Taiwan; Tel: +886-3-4638800 3095; Fax: +886-3-4555574; E-mails: s988706@mail.yzu.edu.tw, fangbor@saturn.yzu.edu.tw
}

catalytic reactors, heat exchangers, filtration, shock absorbers, electrodes, and fuel cell flow fields [1]. Generally, the metal materials used most for metal foams are aluminum, copper, nickel, and stainless steel. Their purpose is to achieve better thermal conductivity and high tensile strength [1].

Using metal foam to replace conventional flow field plates may reduce their thickness and weight due to the low permeability and high mechanical strength of metal foam [2-4]. Metal foam flow fields may also have a higher contact area and level gas transport flow field. According to Kumar and Reddy's research, they have used porous media, such as graphite cloth and metal foam, to replace conventional flow field materials [2-4]. Their simulation results show that metal foam flow fields have more uniform current distribution than conventional ones [2]. In their studies, the operation condition was usually $\sim 80^{\circ} \mathrm{C}$ and $207 \mathrm{kPa}$ high back pressures. Under these conditions, the metal foam flow field had better performance than the conventional flow field. In their studies, they showed that when the operation temperatures was adjusted from $80^{\circ} \mathrm{C}$ to $40^{\circ} \mathrm{C}, 207 \mathrm{kPa}$ back pressure and $0.6 \mathrm{~V}$ operation voltage, the current density decreased by $47 \%$ (from 580 to $310 \mathrm{~mA} \mathrm{~cm}^{-2}$ ) [3]. When the back pressure was adjusted from 207 to $69 \mathrm{kPa}, 80^{\circ} \mathrm{C}$ operation temperatures, and $0.6 \mathrm{~V}$ operation voltage, the current density decreased by $37 \%$ (from 580 to $360 \mathrm{~mA} \mathrm{~cm}{ }^{-2}$ ) [3]. 
We sought to examine why the performance of PEMFCs with metal foam flow fields was much worse at low temperatures and ambient pressure. We also modified the metal foam flow field by adding additional ribs to making a multi-segment foam flow field.As a result, the current density improved by $51 \%$ (from 178 to $269 \mathrm{~mA} \mathrm{~cm}^{-2}$ ). Additionally, the peak power density increased $70 \%$. This type of flow field has the potential to reduce both volume and weight, and it is suitable for developing a small portable PEMFC system. The ambient pressure, low temperatures, and low humidity are helpful to reduce system volume and weight by removing back pressure and humidity components from the system. Concerning PEMFC durability however, the nickel foam should be replaced by durable metal foam or carbon foam [5].

\section{EXPERIMENT SET-UP}

A $25 \mathrm{~cm}^{2}$ single cell was used, its anode and cathode flow field plates were nickel foam and conventional serpentine. The current collection plate was made of gold-coated brass. In this study, an ETEK Series 12E-W membrane electrode assembly (MEA) with carbon cloth GDL, Nafion $112,1.0 \mathrm{mg} \mathrm{cm}^{-2}$ platinum loading (anode and cathode), and $25 \mathrm{~cm}^{2}$ active electrode areas was fitted to the test cell and operated under identical conditions.

The single cell was tested in a Scribner integrated fuel cell test station $850 \mathrm{C}$. The cell temperatures and humidifier temperatures were controlled at $40^{\circ} \mathrm{C}$ and $30^{\circ} \mathrm{C}$, and the hydrogen and air feed rate were 500 sccm and $2000 \mathrm{sccm}$. The depth of the foam flow fields was $0.7 \mathrm{~mm}$. The porosity, permeability, and thickness of the nickel foam were about $0.925,7.205 \times 10^{-11} \mathrm{~m}^{2}$, and $0.75 \mathrm{~mm}$. We designed three different foam flow field in this work, one segment (no ribs), three segments, and five segments. For multi-segment foam flow fields, the width of the segment outlets was 1.0 $\mathrm{mm}$. Figure 1 shows the schematics of the three flow field plates, named foam1, foam3, and foam5. For comparative purposes, we also produced a conventional serpentine flow field. The width of the ribs, width of the channels, and depth of the channels were all $1.0 \mathrm{~mm}$ in the conventional serpentine case. The equivalent permeability $(\alpha)$ is defined in equation (1) [6]:

$$
\alpha=\frac{N_{c}(\Delta z / 2)^{2} \Delta x_{c}}{L} \times\left[\frac{1}{3}-\left(\frac{64}{\pi^{5}}\right) \frac{\Delta Z}{\Delta x_{c}} \sum_{\substack{n \\ \text { odd }}}^{\infty} \frac{1}{n^{5}} \tanh \left(\frac{n \pi \Delta x}{2 \Delta z}\right)\right]
$$

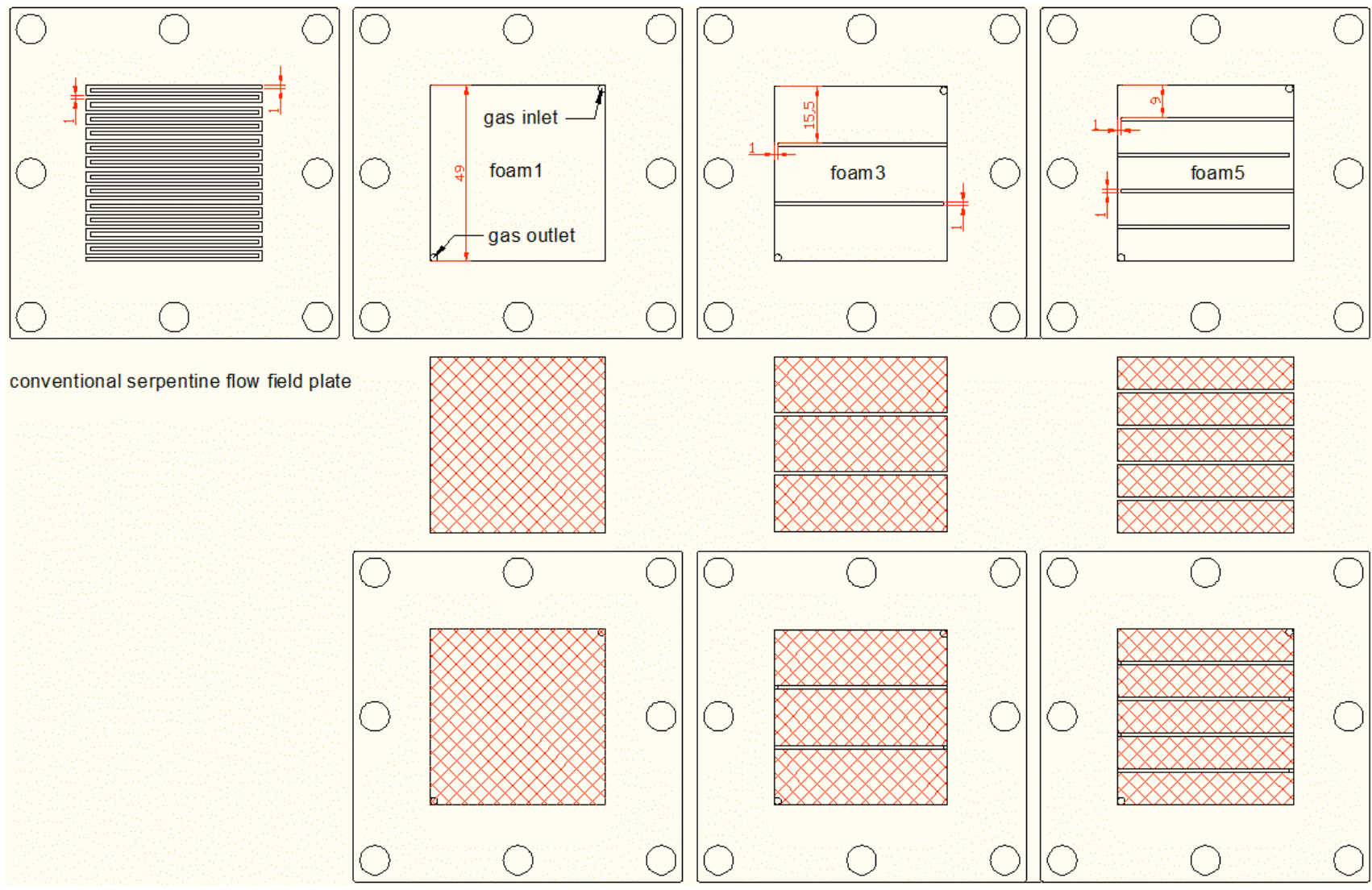

Figure 1: Flow field plate schematics (from left to right): conventional serpentine flow field plate, foam1, foam3, and foam5. 
where $N_{c}$ is the number of channels, $\Delta x_{c}$ is the channel width, $\Delta z$ is the thickness of the channels, and $L$ is the length of the channel. The equivalent permeability of the serpentine flow field is $2.761 \times 10^{-11} \mathrm{~m}$, slightly lower than that of the nickel foam used in this study, but still of the same order of magnitude. All of the flow field plates, including the conventional serpentine flow field, were manufactured with gold-coated aluminum.

The Scribner integrated fuel cell test station $850 \mathrm{C}$ is a performance test station and an electrochemical impedance spectrum (EIS) instrument. In the EIS experiment, the frequency scans were carried out from $10 \mathrm{k}$ to $0.1 \mathrm{~Hz}$, and the amplitude was $10 \%$ of the DC current. The EIS data were fit from $1 \mathrm{k}$ to $1 \mathrm{~Hz}$ using ZView. The high frequency resistance (HFR) was measured at $1 \mathrm{kHz}$.

\section{RESULTS AND DISCUSSION}

\subsection{Polarization Curve}

Figure 2 shows that more segments in foam flow field plate lead to better performance. This result can be attributed to the fact that as the segments increased cause the mass transport resistance decreased. At very low current density, the polarization curve is almost the same. The polarization curves of foam1, foam3, and foam5 were compared to serpentine, and apparent variation occurred at 50,250, and $350 \mathrm{~mA}$ $\mathrm{cm}^{-2}$. Because we used the MEA, foam1, foam3, and foam5 should have similar activation polarizations. The difference of polarization curves results from different ohmic and mass transport resistance. Foam1 has a larger ohmic resistance than the others, which are shown in Figure 2 and Table 1. The peak power density increased $70 \%$ (from 162.1 to $275.2 \mathrm{~mW} \mathrm{~cm}^{-2}$ ) in multi-segment simply because the ribs were added. The very worst performance of foam 1 can be attributed to membrane dehydration. The membrane dehydration resulted from generating less water and high mass transport resistance. Kim et al. (1995) described the mass transport loss by equation (2) [7]:

$$
\Delta V_{\text {trans }}=m \exp (n i)
$$

where $m$ and $n$ are experimental coefficients. The experimental data was fit to equation (2) to determine the $m$ an $n$ values of each of the flow filed plates. The $m$ and $n$ values of foam 1 , foam3, and foam 5 are shown in Table 1. The lower value of $m$ signifies that the mass transport occurs earlier, and the higher value of $n$ means that the voltage drops dramatically during the

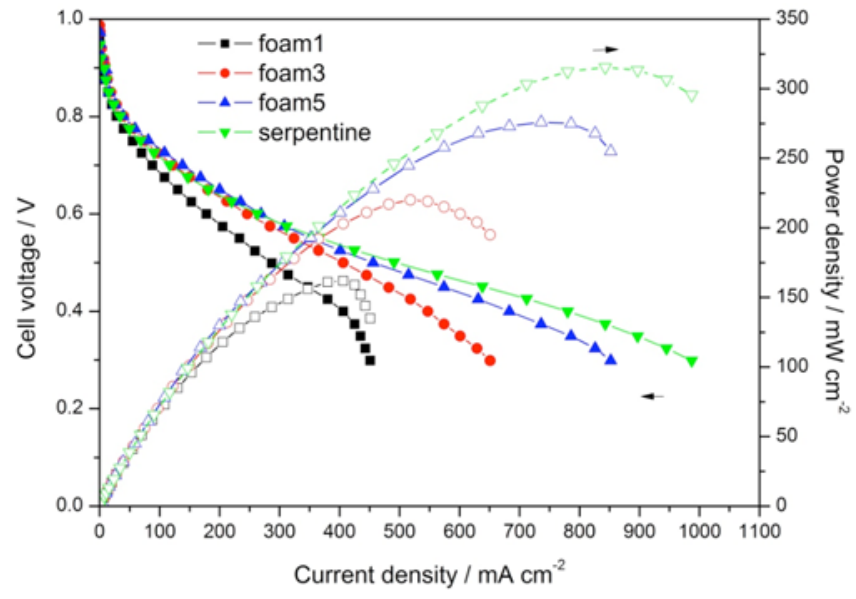

Figure 2: Polarization curves of the different flow field plates. The operating temperature and relative humidity were $40^{\circ} \mathrm{C}$ and $58 \%$. The $500 \mathrm{sccm}$ of hydrogen and $2000 \mathrm{sccm}$ of air were fed. The cell operate with ambient pressure.

mass transport area. Because foam1 has the lowest $m$ and highest $n$, the mass transport happens earliest and decreases fastest (Table 1). Foam5 and serpentine show different $m$ and $n$ values (Table 1), result in why the mass transport of foam5 occurs earlier and decreases to a greater degree than serpentine. This indicates that serpentine retains better performance in the low operation voltage region. Foam 1 has four orders magnitude of $m$ value less than serpentine and an $n$ value about four times greater than serpentine. Thus, the polarization curve of foam 1 drops early and significantly. At high or middle operation voltages, serpentine is not the best choice. Due to the HFR values of $0.8 \mathrm{~V}$ and $0.6 \mathrm{~V}$, serpentine is not the lowest. The ohmic resistance includes contact resistance and membrane resistance. At $0.8 \mathrm{~V}$, the generated water can easily remove because the inlet gas was unsaturated. Therefore, the membrane resistance was nearly the same for all flow field plates, and main difference of ohmic resistance was contributed by contact resistance. The HFR from low to high were foam5, foam3, and serpentine. At $0.6 \mathrm{~V}$, more water was generated and the difference of membrane resistance cannot be ignored. Thus, the HFR from low to high was changed to foam5, serpentine, and foam3. At $0.4 \mathrm{~V}$, a significant amount of water was generated, especially in the case of serpentine. Because the serpentine case generated so much water, the membrane resistance dropped dramatically. Result in the HFR of serpentine was the lowest at this condition. Although the performance of serpentine was higher than foam5 at $0.4 \mathrm{~V}$, the performance of foam5 was a slightly greater than serpentine at $0.6 \mathrm{~V}$. The stack is usually operated at $0.6 \mathrm{~V}$ per unit cell due to higher efficiency compared with $0.4 \mathrm{~V}$. 
Table 1: HFR, Mass Transport Coefficients, and Peak Power Density of Different Flow Field Plates

\begin{tabular}{|c|c|c|c|c|c|c|}
\hline & \multicolumn{3}{|c|}{ HFR $\left(\mathbf{m} \Omega \mathbf{~ c m}^{2}\right)$} & \multicolumn{1}{c|}{$\Delta \mathbf{V}_{\text {trans }}=$ mexp(ni) } & \multirow{2}{*}{ peak power density $\left(\mathbf{m W} \mathbf{~ c m}^{-2}\right)$} \\
\cline { 2 - 6 } & $\mathbf{0 . 8 V}$ & $\mathbf{0 . 6 V}$ & $\mathbf{0 . 4 V}$ & $\mathbf{m}(\mathbf{V})$ & $\mathbf{n}\left(\mathbf{c m}^{\mathbf{2}} \mathbf{~ m A}^{-1}\right)$ & 162.1 \\
\hline \hline foam1 & 880.1 & 748.4 & 682.1 & $1.8 \mathrm{E}-11$ & 0.04499 & 219.7 \\
\hline foam3 & 646.0 & 514.2 & 547.4 & $4.2 \mathrm{E}-08$ & 0.02145 & 275.5 \\
\hline foam5 & 373.5 & 416.2 & 365.4 & $9.1 \mathrm{E}-08$ & 0.01396 & 380.6 \\
\hline serpentine & 670.9 & 485.4 & 343.6 & $2.2 \mathrm{E}-07$ & 0.01172 & \\
\hline
\end{tabular}

\subsection{Electrochemical Impedance Spectrum and Fitting Results}

Figures $\mathbf{3 a}$ and $\mathbf{3} \mathbf{b}$ show the Nyquist plots of different flow fields while the operating voltages at 0.8 $\mathrm{V}$ and $0.6 \mathrm{~V}$. The equivalent circuit is shown in Figure 4 [8], and the fitting result of $R_{\text {ohm }}$ is shown in Table 2. From the EIS results, foam5 showed the minimum internal resistance in the equivalent circuit element, $\mathrm{R}_{\mathrm{ohm}}$. The additional ribs not only affect the contact resistance but also the water saturation. The GDL under solid ribs had more water saturation than it did under the channels [9]. The MEA temperature, especially the cathode catalyst layer, was higher than that of the GDL and flow field [9]. The solid ribs had higher thermal conductivity, which made the temperatures of the ribs lower than it was under the channels; thus, water condensed under the ribs [9]. Because the foam had higher thermal conductivity, the foam flow field had a greater chance of water flooding than the serpentine. Additionally, the dehydration of the GDL under the solid ribs was more difficult because it had a high compression ratio. These results demonstrated that greater numbers of segments reduced the mass transport resistance, leading to better performance and generating more water to hydrate the MEA. Foam is softer than solid ribs and has a greater area in contact with the GDL. Therefore, the contact resistance of the foam flow field plates is smaller than that of serpentine. As a result, foam5 has the lowest $R_{\text {ohm }}$.

\subsection{Two Hour Time Stability Test}

The long time test of different flow field was conducted at a constant $0.4 \mathrm{~V}$ for $2 \mathrm{~h}$, and the results are shown in Figure $\mathbf{5}$. It is clear that the current density is highly related to the HFR in every case. For the foam field, MEA dehydration would condense on the foam due to the flow field temperatures being lower than the MEA. Water blocked in the pores of the foam and decreased performance due to the increase of mass transport resistance. When water was evacuated from the pores, it could hydrate the MEA, decrease the $\mathrm{HFR}$, and enhance the performance. Because the single serpentine had only one channel, the water could not block the channel for a long time. When the flooding water of the GDL under the ribs was purged, it
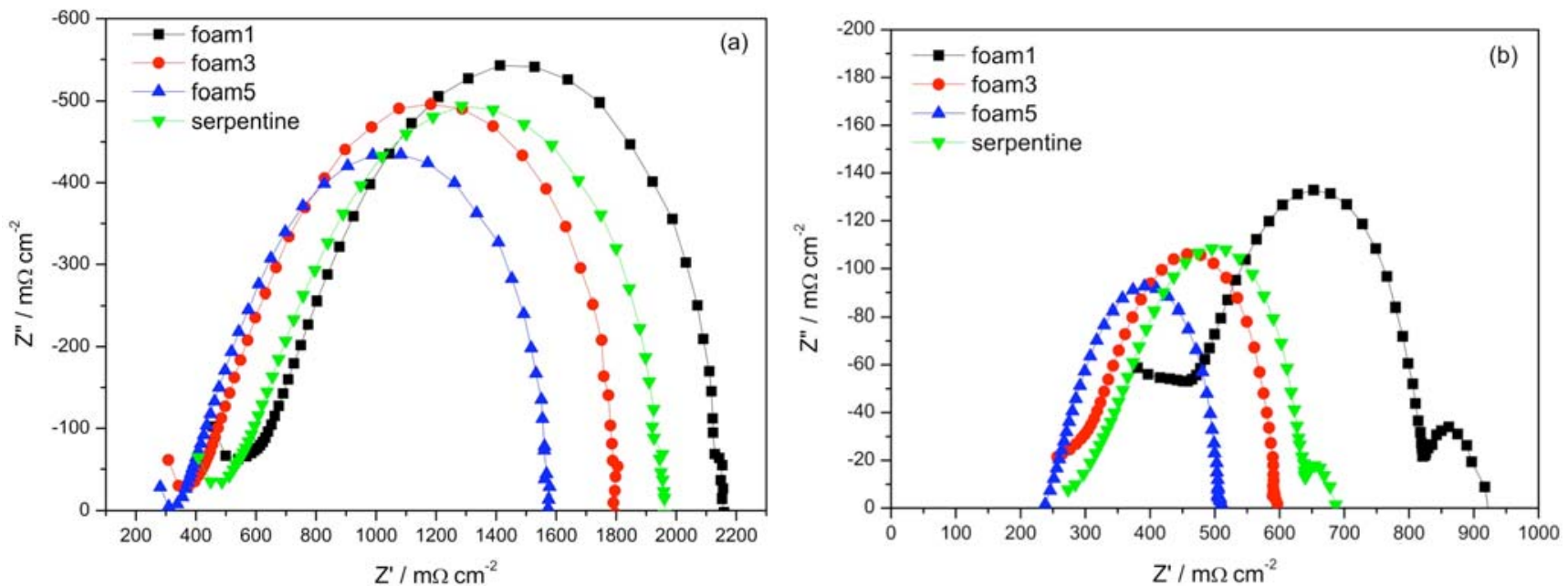

Figure 3: Nyquist plot of different flow field plate operation at constant $0.8 \mathrm{~V}(\mathbf{a})$ and $0.6 \mathrm{~V}$ (b). The operating temperature and relative humidity were $40^{\circ} \mathrm{C}$ and $58 \%$. The $500 \mathrm{sccm}$ of hydrogen and $2000 \mathrm{sccm}$ of air were fed. The cell operated with ambient pressure. 


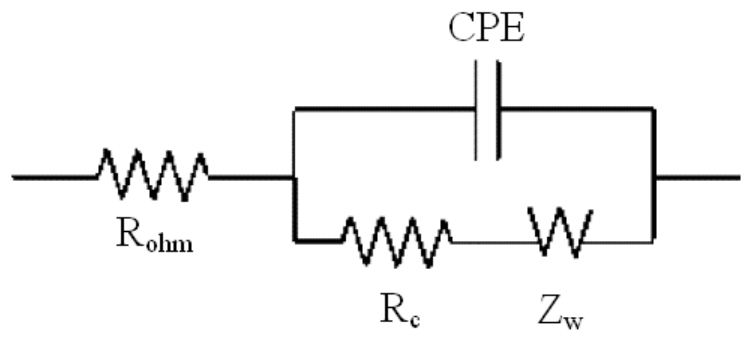

Figure 4: Equivalent circuits for fitting the EIS results.

Table 2: EIS Fitting Result in Different Flow Field Plates at 0.8 and $0.6 \mathrm{~V}$

\begin{tabular}{|c|c|c|c|c|}
\hline \multirow{2}{*}{} & \multicolumn{2}{|c|}{$\mathbf{R}_{\text {ohm }}\left(\mathbf{\Omega} \mathrm{cm}^{2}\right)$} & \multicolumn{2}{c|}{ Normalized $\mathbf{R}_{\text {ohm }}(\%)$} \\
\cline { 2 - 5 } & $\mathbf{0 . 8 V}$ & $\mathbf{0 . 6 V}$ & $\mathbf{0 . 8 V}$ & $\mathbf{0 . 6 V}$ \\
\hline \hline foam1 & 0.6103 & 0.4635 & 111.33 & 138.45 \\
\hline foam3 & 0.4251 & 0.3066 & 77.55 & 91.56 \\
\hline foam5 & 0.3808 & 0.2609 & 69.46 & 77.92 \\
\hline serpentine & 0.5482 & 0.3348 & 100.00 & 100.00 \\
\hline
\end{tabular}

could hydrate the MEA as well, but those GDLs were highly compressed such that the chance of water
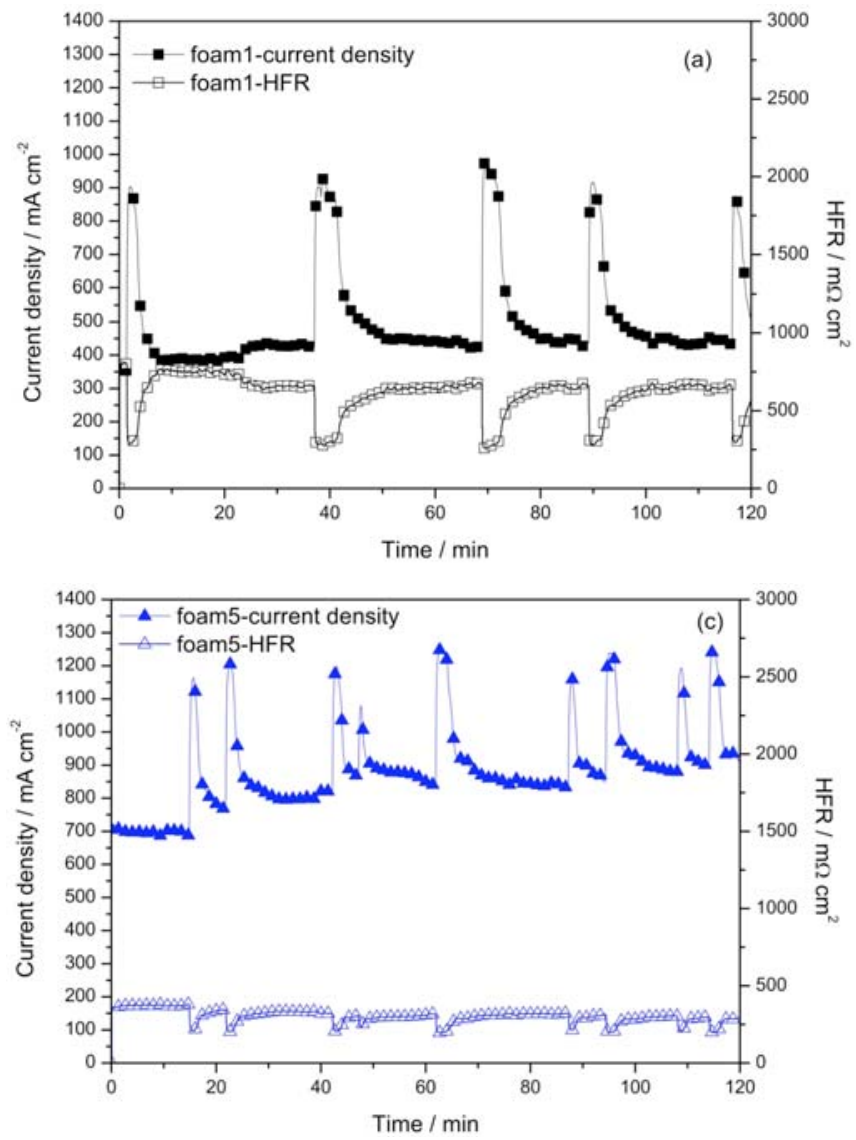

evacuation was slight. Therefore, the performance of the serpentine flow field increased less than the foam flow fields, and fewer peaks also occurred.

The result of maximum current density $\left(\mathrm{i}_{\max }\right)$, minimum current density $\left(\mathrm{i}_{\min }\right), \Delta \mathrm{i}\left(\Delta \mathrm{i}=\mathrm{i}_{\max }-\mathrm{i}_{\min }\right)$, the average peak current density, and the average peak current density period time during this 2 hrs test are listed in Table 3. First, comparing foam5 to the other foam flow field plates, foam5 had a better performance of $\mathrm{i}_{\max }, \mathrm{i}_{\min }$, and average peak current density. This result indicated that more segments led to better performance. Compared to other foam flow fields, foam5 has the lowest $\Delta \mathrm{i}$, average peak current density period time, and standard deviation. This result implied that with more segments, the flooding water could be purged more quickly, and that contributed to less flooding and greater stability. The results mentioned above can be attributed to the ribs separating the flow field into several segments, decreasing their areas. These smaller areas increased the fuel velocity in each segment, and the water was purged quickly. Comparing the values of foam5 with those of serpentine, the serpentine had higher $\mathrm{i}_{\min }$, higher $\Delta \mathrm{i}$,
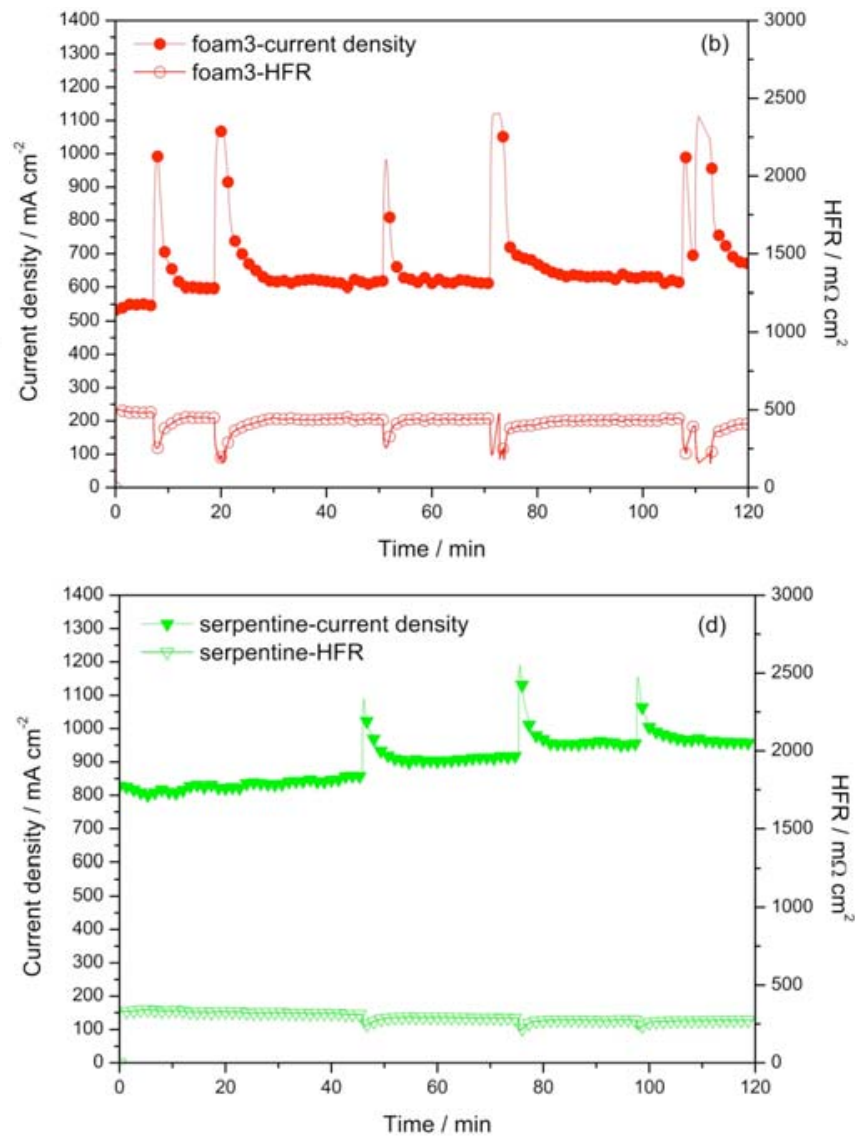

Figure 5: Current density and HFR vs. time in the long test with foam1 (a), foam3 (b), foam5 (c), and serpentine (d) at constant $0.4 \mathrm{~V}$. The operating temperature and relative humidity were $40^{\circ} \mathrm{C}$ and $58 \%$. The $500 \mathrm{sccm}$ of hydrogen and $2000 \mathrm{sccm}$ of air were fed. The cell operated with ambient pressure. 
Table 3: The Coordination Results of the Long Time Test

\begin{tabular}{|c|c|c|c|c|}
\hline & foam1 & foam3 & foam5 & Serpentine \\
\hline $\mathrm{i}_{\max }\left(\mathrm{mA} \mathrm{cm} \mathrm{cm}^{-2}\right)$ & 984.5 & 1137.5 & 1253.3 & 1190.2 \\
\hline $\mathrm{i}_{\min }\left(\mathrm{mA} \mathrm{cm} \mathrm{cm}^{-2}\right)$ & 349.7 & 532.1 & 684.8 & 800.2 \\
\hline$\Delta \mathrm{i}=\mathrm{i}_{\max }-\mathrm{i}_{\min }\left(\mathrm{mA} \mathrm{cm}{ }^{-2}\right)$ & 634.8 & 605.4 & 568.5 & 390.0 \\
\hline average of current density $\left(\mathrm{mA} \mathrm{cm}^{-2}\right)$ & 501.2 & 675.7 & 886.6 & 906.2 \\
\hline Standard deviation $\left(\mathrm{mA} \mathrm{cm} \mathrm{cm}^{-2}\right)$ & 149.4 & 130.1 & 130.0 & 70.0 \\
\hline Average of peak current density $\left(\mathrm{mA} \mathrm{cm}^{-2}\right)$ & 926.7 & 1061.5 & 1196.6 & 1172.2 \\
\hline Average of peak current density period time (min) & 28.73 & 20.74 & 12.42 & 25.87 \\
\hline
\end{tabular}

and a lower standard deviation, and this situation indicated that serpentine had better basic performance and greater stability. For $\mathrm{i}_{\max }$ and the average peak current density, foam5 showed a better performance than the serpentine. This result may be attributed to the fact that when the MEA was hydrated, foam5 had lower contact resistance, which led to a higher $\mathrm{i}_{\max }$ and average current density. Interestingly, for the average peak current density period time, foam5 had a shorter time period, and this is because foam5 purged the water quickly. Comparing foam5 with serpentine, foam5 had worse $\Delta \mathrm{i}$. The result of $\Delta \mathrm{i}$ implied that the serpentine flow field was more stable. The serpentine also had a longer time period due to its highly compressed GDL. And, the average current density of foam5 was very close to that of serpentine during this test. Thus, we can conclude that the foam flow field has a greater chance of better performance than the serpentine by adding more ribs.
Figure $6 \mathrm{a}$ shows the EIS at $0.4 \mathrm{~V}$ before the long time test, and Figure $\mathbf{6 b}$ shows the EIS after the long time test. The fitting results are shown in Table 4. Comparing the $R_{\text {ohm }}$ before and after the long time test, it obviously shows that the MEA was hydrated after the long time test, and therefore $R_{\text {ohm }}$ decreased dramatically. Comparing the $R_{\text {ohm }}$ of different flow field plates, the sequence of $R_{\text {ohm }}$ from high to low was foam1, foam3, foam5, and serpentine. This result can be attributed to the water yield was different in foam1, foam3, foam5. Some flow field plates even showed that the Warburg impedance $\left(Z_{w}\right)$ was reduced after the long time test. This reduction may be attributed to the hydrated catalyst layer increasing the three boundary phases. Notice that the $Z_{w}$ of foam5 was much lower than the other foam flow field plates. This may be attributed to foam5 had lower mass transport resistance before and after the long time tests [6]. The lower $Z_{w}$ value of foam5 implied that adding ribs would help decrease the mass transport resistance in the
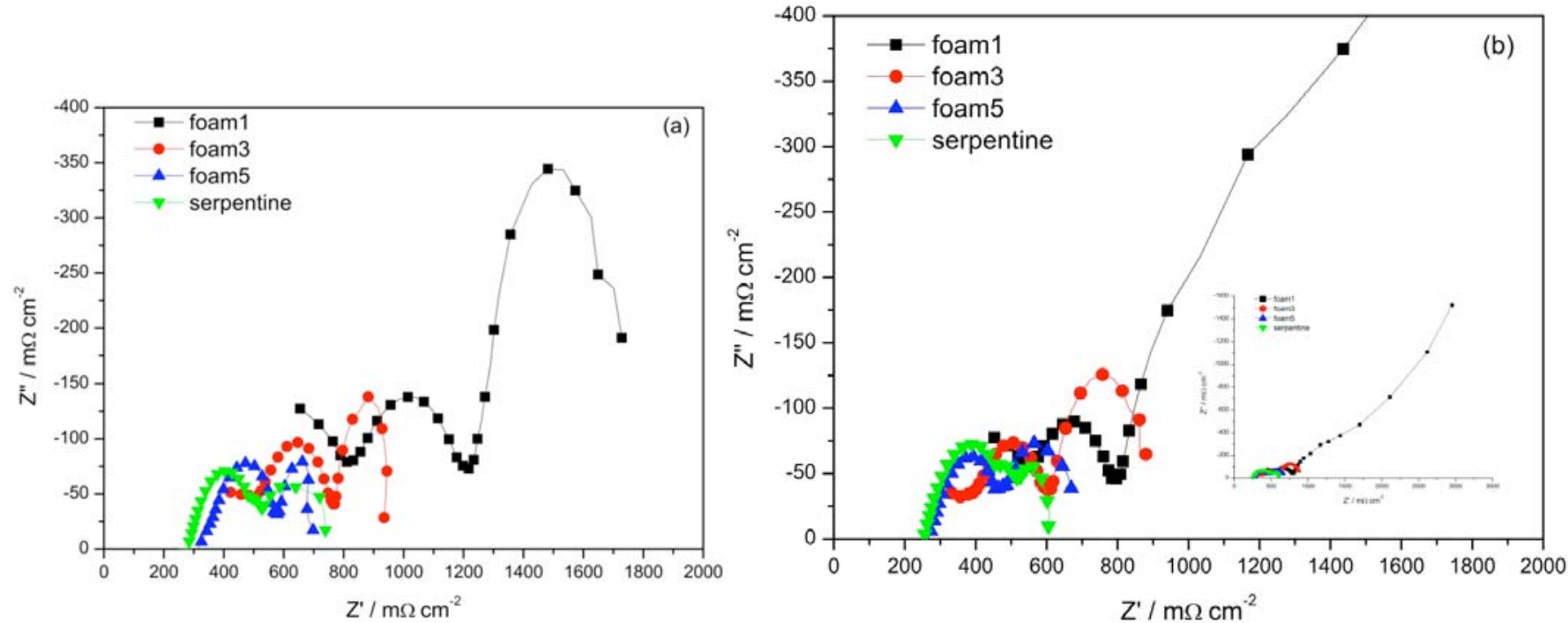

Figure 6: Nyquist plot of different flow field plates at constant $0.4 \mathrm{~V}$ before (a) and after (b) the long time test. The operating temperature and relative humidity were $40^{\circ} \mathrm{C}$ and $58 \%$. The $500 \mathrm{sccm}$ of hydrogen and $2000 \mathrm{sccm}$ of air were fed. The cell operated with ambient pressure. 
Table 4: EIS Fitting Result in Different Flow Field Plates at $0.4 \mathrm{~V}$

\begin{tabular}{|c|c|c|c|c|c|c|c|c|}
\hline & \multicolumn{4}{|c|}{ Before $0.4 \mathrm{~V}$ long time test } & \multicolumn{4}{|c|}{ After $0.4 \mathrm{~V}$ long time test } \\
\hline & foam1 & foam3 & foam5 & serpentine & foam1 & foam3 & foam5 & serpentine \\
\hline $\mathrm{R}_{\mathrm{ohm}}\left(\Omega \mathrm{cm}^{2}\right)$ & 0.7804 & 0.4949 & 0.3540 & 0.2805 & 0.5135 & 0.3769 & 0.2749 & 0.2516 \\
\hline \multirow[t]{4}{*}{$\mathrm{Z}_{\mathrm{w}}\left(\Omega \mathrm{cm}^{2}\right)$} & 1.8049 & 1.1400 & 0.7110 & 0.3937 & 1.1059 & 1.0224 & 0.7224 & 0.3892 \\
\hline & \multicolumn{8}{|c|}{ Normalize } \\
\hline & \multicolumn{4}{|c|}{ Before $0.4 \mathrm{~V}$ long time test } & \multicolumn{4}{|c|}{ After $0.4 \mathrm{~V}$ long time test } \\
\hline & foam1 & foam3 & foam5 & serpentine & foam1 & foam3 & foam5 & serpentine \\
\hline $\mathrm{R}_{\mathrm{ohm}}(\Omega)$ & 278.22 & 176.43 & 126.19 & 100.00 & 204.12 & 149.83 & 109.25 & 100.00 \\
\hline $\mathrm{Z}_{\mathrm{w}}(\Omega)$ & 458.42 & 289.54 & 180.57 & 100.00 & 284.18 & 262.71 & 185.64 & 100.00 \\
\hline
\end{tabular}

foam flow field. The $Z_{w}$ value of foam5 was higher than the serpentine. In other words, performance can be improved by adding more ribs.

\subsection{High Temperature Proton Exchange Membrane Fuel Cell Test}

The above results demonstrate liquid water effect performance significantly in low-temperature PEMFC with foam and. This section applied the multi-segment (3 segment) compare with conventional serpentines flow field for the performance test with a commercial high temperature MEA (Advent TPS). The activation area of this MEA was $31.4 \mathrm{~cm}^{2}$ and test under $160^{\circ} \mathrm{C}$ with dry hydrogen and air as fuel and oxidant. There are two cases in this section: first, conventional graphite multi-serpentines flow field. Second, 3 segments metal foam flow field (foam3-HT). The result shown as Figure 7, there are no significant difference between this two flow fields. This result implies foam multi-segments foam flow filed has possible to replace

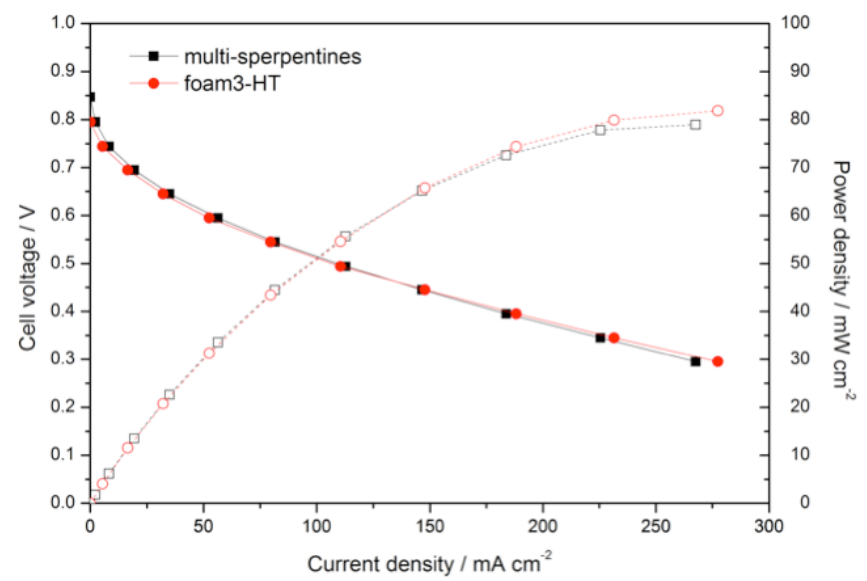

Figure 7: Polarization curves of the different flow field plates with high temperature fuel cell. The operating temperature was $160^{\circ} \mathrm{C}$. The anode and cathode flow rate were 300 $\operatorname{sccm}\left(\mathrm{H}_{2}\right)$ and $2000 \mathrm{sccm}$ (Air), and operate at ambient pressure with dry gases. conventional flow field, and can reduce the weight and cost for the plates. Because the HT-PEMFC operate in high temperature $\left(160^{\circ} \mathrm{C}\right)$, the generated water vaporized quickly and the effect is small.

\section{CONCLUSION}

Low temperatures and ambient pressure operation were helpful in developing a lighter and smaller portable flow field system. Comparing the foam flow field series, foam5 had the best performance. Foam5 also had better performance in the high and middle voltage regions than the serpentine flow field because it was compressible and had more contacting areas with GDL. For the long time test, foam5 showed the best performance and stability among the foam flow field plates. Adding more ribs improved the performance due to improved mass transport. At $0.4 \mathrm{~V}$, the current density of foam5 during the long time test was nearly the same as the serpentine flow field plate. The most notable result was that foam5 had the best performance at $0.6 \mathrm{~V}$ because the stack usually operates at this voltage per unit cell. This study demonstrates that multi-segment foam flow fields have the possible to replace conventional serpentine flow fields. We suggest further studies for optimization because there are many parameters (e.g., the pores per linear inch of foam, segment number, and width of the segment outlet) that could affect performance.

And also can replace the flow field in HT-PEMFC, the performance is almost the same.

\section{NOMENCLATURE}
$\alpha=$ equivalent permeability
$\mathrm{N}_{\mathrm{c}}=$ number of channels
$\Delta \mathrm{z}=$ thickness of the channels 


$$
\begin{aligned}
& \Delta \mathrm{x}_{\mathrm{c}}=\text { channel width } \\
& \Delta \mathrm{V}_{\text {trans }}=\text { overpotential of mass transport } \\
& \mathrm{m}=\text { experimental coefficient } \\
& \mathrm{n}=\text { experimental coefficient } \\
& \mathrm{i}_{\max }=\text { maximum current density } \\
& \mathrm{i}_{\min }=\text { minimum current density } \\
& U=\operatorname{velocity}(\mathrm{m} / \mathrm{s}) \\
& \varepsilon \quad=\text { porosity } \\
& \mathrm{T}=\text { shear force tension } \\
& h=\text { enthalpy } \\
& s=\text { saturation } \\
& \mathrm{K}=\text { permeability }\left(\mathrm{m}^{2}\right) \\
& \mu \quad=\quad \text { viscosity }\left(\mathrm{m}^{2} / \mathrm{s}\right) \\
& \mathrm{Y}_{\mathrm{i}}=\text { mass-fractions of the } \mathrm{i}^{\mathrm{th}} \text { species } \\
& \omega_{i}=\text { production rates of the } i^{\text {th }} \text { species in the gas } \\
& \text { phase } \\
& \mathrm{J}_{\mathrm{i}}=\text { diffusion flux } \\
& \text { is }=\text { in porous media, the current flowing through } \\
& \text { the pores }(A) \\
& \mathrm{i}_{\mathrm{F}}=\text { in porous media, the current flowing through } \\
& \text { the solid parts of the porous matrix }(A) \\
& \mathrm{F}=\text { Faraday constant } \\
& \mathrm{j}_{0}=\text { reference current }\left(\mathrm{A} / \mathrm{m}^{3}\right)
\end{aligned}
$$
$\alpha_{\mathrm{a}}=$ anode kinetic constant
$\alpha_{\mathrm{c}}=$ cathode kinetic constant
$[\wedge]=$ the near-wall molar concentration of the reacting species
$\Phi_{\mathrm{s}} \quad=$ solid potential (V)
$\Phi_{\mathrm{F}} \quad=$ fluid potential (V)

\section{REFERENCES}

[1] Miwa S, Revankar ST. Hydrodynamic Characterization of Nickel Metal Foam, Part 1: Single-Phase Permeability. Transport in Porous Media 2009; 80: 269. http://dx.doi.org/10.1007/s11242-009-9356-7

[2] Kumar A, Reddy RG. Modeling of polymer electrolyte membrane fuel cell with metal foam in the flow-field of the bipolar/end plates. J Power Sour 2003; 114: 54. http://dx.doi.org/10.1016/S0378-7753(02)00540-2

[3] Kumar A, Reddy RG. Polymer Electrolyte Membrane Fuel Cell with Metal Foam in the Gas Flow-Field of Bipolar/End Plates. J New Mater Electrochem Syst 2003; 6: 231.

[4] Kumar A, Reddy RG. Materials and design development for bipolar/end plates in fuel cells. J Power Sour 2004; 129: 62. http://dx.doi.org/10.1016/j.jpowsour.2003.11.011

[5] Kim J, Cunningham N. Development of porous carbon foam polymer electrolyte membrane fuel cell. J Power Sour 2010; 195: 2291. http://dx.doi.org/10.1016/j.jpowsour.2009.10.053

[6] Hontañón E, Escudero MJ, Bautista C, García-Ybarra PL, Daza L. Optimization of flow-field in polymer electrolyte membrane fuel cells using computational fluid dynamics techniques. J Power Sour 2000; 86: 363.

[7] Kim J, Lee SM, Srinivasan S, Chamberlin CE. Modeling of Proton Exchange Membrane Fuel Cell Performance with an Empirical Equation. J Electrochem Soc 1995; 142: 2670.

[8] Lobato J, Rodrigo MA, Linares JJ, Scott K. Effect of the catalytic ink preparation method on the performance of high temperature polymer electrolyte membrane fuel cells. J Power Sour 2006; 157: 284. http://dx.doi.org/10.1016/j.jpowsour.2005.07.040

[9] Chi PH, Weng FB, Su A, Chan SH. Numerical modeling of proton exchange membrane fuel cell with considering thermal and relative humidity effects on the cell performance. J Fuel Cell Sci Technol 2006; 3: 292. http://dx.doi.org/10.1115/1.2211632 